\title{
Os conteúdos atitudinais e o educar pela pesquisa na educação de jovens e adultos
}

The attitudinal contents and education by research in youth and adult education

Thelma Duarte Brandolt Borges ${ }^{a}$, Valderez Marina do Rosário Lima ${ }^{b}$

\section{Editor}

Maria Inês Côrte Vitoria PUCRS, RS, Brasil

\section{Equipe Editorial}

Pricila Kohls dos Santos PUCRS, RS, Brasil

Marcelo Oliveira da Silva PUCRS, RS, Brasil

Carla Spagnolo

PUCRS, RS, Brasil

Rosa Maria Rigo

PUCRS, RS, Brasil
RESUMO: Esta pesquisa foi realizada com o intuito de investigar as contribuições do Educar pela Pesquisa parao desenvolvimento de conteúdos atitudinais na Educação de Jovens e Adultos (EJA). Para isso, 26 estudantes dessa modalidade participaram de uma sequência didática preparada sob os fundamentos dessa prática pedagógica, os quais envolvem o questionamento, a construção de argumentos e a comunicação. As informações coletadas revelaram que a estratégia de ensino favoreceu o desenvolvimento da autoestima e autonomia dos estudantes e beneficiou o relacionamento interpessoal em sala de aula, promovendo um clima de cooperação e contribuindo, assim, para uma mudança de atitude em relação à participação dos estudantes como sujeitos no processo de ensino e aprendizagem.

Palavras-chave: educar pela pesquisa; conteúdos atitudinais; educação de jovens e adultos.

ABSTRACT: This research was conducted in order to investigate the contributions of Education by Research for the development of attitudinal content in the Youth and Adult Education. For this, 26 students of this modality participated in a teaching sequence prepared under the foundations of this pedagogical practice which involves questioning, building arguments and communication. The information gathered revealed that the teaching strategy favored the development of self- esteem and autonomy of students, benefited the interpersonal relationships in the classroom, promoting a climate of cooperation, contributing to a change of attitude towards participation as students as subjects in the process of teaching and learning.

Keywords: educating for research; attitudinal contents; youth and adult education.

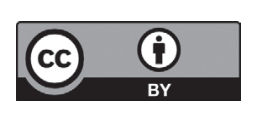

Este artigo está licenciado sob forma de uma licença Creative Commons Atribuição 4.0 Internacional, que permite uso irrestrito, distribuiçăo e reproduçáa em qualquer meio, desde
seja corretamente citada. http://creativecommons.org/licenses/by/4.0/deed.pt_BR

\footnotetext{
a Mestre em Educação em Ciências e Matemática pela PUCRS.

b Doutora em Educação. Professora permanente dos Programas de Pós-Graduação em Educação (Faculdade de Educação) e em Educação em Ciências e Matemática (Faculdade de Física) da PUCRS.
} 


\section{Introdução}

inda que não sejam ensinados de modo deliberado, ou talvez justamente por não o serem, os conteúdos atitudinais constituem uma das principais dificuldades para o ensino e a aprendizagem das ciências, configurando-se em um tema relevante e complexo.

Zabala (1998) os define como aqueles referentes à forma como cada pessoa realiza sua conduta de acordo com valores determinados. Nesse sentido, as atitudes são assumidas como "tendências ou disposições relativamente duradouras para avaliar de modo determinado um objeto, pessoa, acontecimento ou situação e atuar de acordo com essa avaliação" (COLL et al. 1998, p. 122).

Fica evidente, portanto, a indissociabilidade dos aspectos atitudinais de toda atividade humana, permeando, por conseguinte, qualquer prática educativa. Tal entendimento reforça a importância de trabalhar aspectos que se relacionem aos valores, às normas e aos juízos de cada indivíduo, com consequências que ultrapassamos limites da sala de aula na medida em que são aprendizagens que contribuem para a atuação em grupos sociais.

A Educação de Jovens e Adultos (EJA) é uma modalidade educacional com altos índices de evasão em que se percebem relações afetivas ainda mais complexas e, em grande parte, determinadas pelas vivências do mundo social dos sujeitos. Nesse contexto, a consideração e a inclusão dos conteúdos atitudinais no currículo merecem destaque ainda maior.

Partindo da necessidade de repensar o modo de trabalho com vistas a desenvolver conteúdos atitudinais na EJA, optou-se por utilizar uma metodologia de ensino alinhada à concepção construtivista dos processos de ensino e aprendizagem com o objetivo de investigar as contribuições do Educar pela Pesquisa para o desenvolvimento de conteúdos atitudinais na EJA.

No artigo ora apresentado, detalha-se o caminho percorrido na tentativa de responder à pergunta: Quais as contribuições do Educar pela Pesquisa para o desenvolvimento de conteúdos atitudinais na EJA? Para isso, o texto encontra-se organizado em cinco partes. A Introdução, considerada a primeira seção, apresenta o tema de estudo e sua importância, assim como a questão de pesquisa. A segunda seção trata da sustentação teórica, esclarecendo a respeito dos tipos de conteúdos curriculares e fundamentando a proposta pedagógica utilizada. Na terceira seção são descritos os aportes metodológicos da pesquisa, como a abordagem e o tipo de pesquisa desenvolvida; o contexto e os sujeitos envolvidos; os instrumentos utilizados para a coleta de dados; e sua forma de análise. Os resultados são apresentados e discutidos na quarta seção. Nela, os dados são explicitados, interpretados e fundamentados. A quinta seção refere-se às considerações finais. Ali se apresenta uma síntese do trabalho, além de reflexões sobre trabalhos futuros. 


\section{Sustentação teórica}

\section{Conteúdos curriculares na EJA}

De acordo com Coll et al. (1998) e Zabala (1998), os conteúdos curriculares podem ser divididos em três categorias: conceituais, procedimentais e atitudinais. Os conteúdos conceituais - comumente mais desenvolvidos em sala de aula - referem-se a fatos, dados e conceitos. Os conteúdos procedimentais aludem às regras, técnicas, destrezas e habilidades. E os conteúdos atitudinais, já definidos introdutoriamente, por seu caráter difuso e transversal, acabam escapando pelos vãos do currículo e perdendo espaço em sala de aula (POZO e CRESPO, 2009).

A carga horária restrita e a maior faixa etária dos estudantes da EJA- muitas vezes habituados a determinadas posturas e normas sociais, com valores já estabelecidos e crenças arraigadas - podem ser fatores que dificultam ainda mais a abrangência dos aspectos atitudinais nesse segmento educacional.

A esse respeito, Correa et al. (2003, p. 40) afirmam que os alunos da EJA geralmente "sentem vergonha de ter parado de estudar, medo do ridículo e do desconhecido, permanecendo na escola por afinidade e não por obrigação". Portanto, é necessário um esforço intencional na atenção às peculiaridades desse grupo diferenciado de estudantes e para os quais a afetividade atua como peça fundamental da prática pedagógica, justificando o enfoque deste recorte da análise.

\section{Metodologia de ensino}

É preciso deslocar o aluno da condição passiva e subalterna, que tem como principais atividades a repetição e a cópia, para a condição de sujeito atuante nas aprendizagens realizadas. Isso é possível por meio da busca ativa de informações, da elaboração própria e da permanente reconstrução do conhecimento (DEMO, 2007). O Educar pela Pesquisa, por meio dos seus princípios de questionamento, construção de argumentos e comunicação (MORAES, GALIAZZI e RAMOS, 2004) surgiu como alternativa possível para suprir a necessidade de processos de ensino mais produtivos e contemplativos de conteúdos atitudinais na EJA.

A partir dessa estratégia de ensino diferenciada, os alunos são instigados a questionar a realidade e o seu próprio conhecimento, a propor ações para obter respostas às suas perguntas, de modo a reconstruir os seus argumentos para comunicar as novas percepções e entendimentos em sala de aula (RAMOS, LIMA e ROCHA-FILHO, 2009). Nesse processo, é preciso superar o estado atual e atingir novos patamares, não só do conhecer e do fazer, mas também do ser, como sugerem Moraes, Galiazzi e Ramos (2004).

Em meio ao processo de troca de saberes e desenvolvimento de habilidades, que esse tipo de trabalho proporciona, optou-se por lançar luz sobre as questões atitudinais, deslocando-as da condição de pano de fundo para dar-lhes 
destaque e acompanhamento, ainda que se tenha consciência de que se tratam de fenômenos fortemente entrelaçados.

\section{Aportes metodológicos}

\section{Metodologia de pesquisa}

Configurando-se como estudo de caso, de natureza qualitativa, a presente investigação possibilitou que se "preservassem as características holísticas e significativas dos acontecimentos" (YIN, 2005, p. 27) vivenciados na prática da sala de aula, focalizando a realidade de forma contextualizada e aprofundada. Esta pesquisa foi desenvolvidaa partir de dados coletados por meio de questionários, diário de campo da pesquisadora e gravações em áudio de sete encontros com alunos de uma turma da EJA do $2^{\circ}$ Segmento (Ensino Médio) em uma escola pública de um município do Estado do Rio Grande do Sul, Brasil. Para preservar a identidade dos participantes, os mesmos foram identificados como sujeitos, seguindo uma numeração do 01 a 26, de acordo com a ordem alfabética dos verdadeiros nomes dos estudantes.

As informações coletadas foram submetidas ao processo de Análise Textual Discursiva, descrito por Moraes e Galiazzi (2011) como um movimento interpretativo com a finalidade de produzir novas compreensões sobre os fenômenos e discursos estudados. Tal análise envolveu três momentos principais: a transcrição dos dados e sua desconstrução para a obtenção de unidades de sentido (unitarização); o estabelecimento de relações e pontos convergentes entre os elementos unitários (categorização); e a comunicação das novas compreensões (metatexto).

\section{Resultados}

Desde o início dessa investigação constatou-se que, para que os alunos se envolvessem em atividades elaboradas em consonância com os princípios do Educar pela Pesquisa e expusessem suas opiniões e pensamentos a respeito das (re)construções necessárias, seria preciso que se sentissem à vontade no seu ambiente de estudos e na presença dos seus colegas e professores. Dessa forma, a própria escolha da metodologia favoreceu o despertar dos conteúdos atitudinais na EJA, aspecto que não só adquiriu um caráter de "pré-requisito para o alcance de objetivos educacionais" (CODO e GAZZOTTI, 1999, p. 50), mas também constituiu-se como um desses objetivos.

No decorrer dos encontros e a partir da análise das informações reunidas por meio dos instrumentos de coleta de dados,foi possível presumir que os estudantes com faixa etária entre 19 e 53 anos pareciam habituados a aulas baseadas em metodologias transmissivas, pois, apesar de terem muito a contribuir para o processo de ensino- 
aprendizagem, em razão de sua historicidade, experiências de vida e de trabalho, papel na família e na sociedade, apresentaram atitudes de resistência inicial às situações de ensino propostas.

Interessante perceber que, quando sondados a respeito de suas preferências, ainda durante o questionário inicial, jovens e adultos sugeriram aulas "Diferentes" (Sujeito 11), "Divertidas, mas de forma que a gente aprenda" (Sujeito 15), "Bem elaboradas e com diálogo" (Sujeito 19), "Com mais conversa" (Sujeito 23), "Que sejam elaboradas para tirar nossas dúvidas" (Sujeito 18). Tais comentários parecem dar abertura a algo novo, indicando uma vontade de expressar-se e fornecendo pistas de que uma providência fundamental seria a construção de um ambiente positivo em sala de aula, o qual pudesse conduzir à participação ativa dos sujeitos a partir de metodologias de ensino mais dialógicas. No entanto, quando convidados a integrar uma alternativa pedagógica específica, mostraram-se, em um primeiro momento, relutantes a essa experiência.

Nas primeiras aulas, por exemplo, o silêncio perante alguns questionamentos foi um indicativo implícito desse fator. Ocorreram, ainda, manifestações explícitas revelando medo de se expor, insegurança, receio de críticas e baixa autoestima. O sujeito 03, por exemplo, justificou dizendo: "Não tenho certeza, então não posso falar nada". Já o sujeito 02 afirmou: "Fica todo mundo olhando estranho". O sujeito 03 esquivou-se dizendo: "Ninguém sabe nada aqui".

Os sentimentos de incerteza, insegurança e menos-valia, reiteradamente associados aos estudantes da EJA, mostraram-se presentes nas falas dos alunos e pareceram ter relação com o protagonismo atribuído aos estudantes no âmbito do Educar pela Pesquisa, ao qual os alunos não estavam habituados. Ocorre que, para que se mude a imagem retrógrada da sala de aula, é preciso "[...] desfazer a noção de aluno como sendo alguém subalterno, tendente a ignorante [...]" (DEMO, 2007, p. 15) e transformá-lo em parceiro de trabalho, o que, em se tratando de jovens e adultos, parece ainda mais natural. Efetivar essa mudança de paradigma requer destreza por parte do professor em um esforço de mobilização dos alunos para a participação nas atividades e de acompanhamento do processo de adaptação metodológica ancorado no âmbito atitudinal.

Percebeu-se, de fato, que a mudança de perspectiva gerada e o próprio ambiente flexível e de imprevisibilidade que o Educar pela Pesquisa proporciona incitaram os alunos a saírem de sua zona de conforto, causando certo estranhamento aos mesmos. Destaca-se, nesse ponto, a impaciência demonstrada pelos estudantes já nos momentos iniciais do processo de descoberta que compunha a sequência didática planejada. Nas situações de questionamento acerca dos conhecimentos prévios, por exemplo, logo almejavam uma resposta definitiva a ser proferida pela professora.

A dificuldade em trabalhar com a dúvida também foi observada e manifesta por alguns alunos no momento de levantamento de hipóteses a respeito de uma situação-problema apresentada. Os fragmentos a seguir ratificam 
tais afirmações: "Mas nós já falamos alguma coisa certa, ou estamos totalmente fora da casinha?" (Sujeito 20). "A senhora ficou fazendo nós discutirmos aqui, falarmos várias coisas... pra nada? Queremos saber a resposta certa!" (Sujeito 15).

Tendo em vista que os estudantes inicialmente não tinham a percepção do "erro como uma forma provisória de saber" (FREIRE e FAUNDEZ, 1998, p. 71), precisaram, ao longo da investigação, de constantes feedbacks com o objetivo de tranquilizá-los e transmitir segurança em relação ao processo e, também, de elevar sua autoestima e aumentar sua confiança para que participassem das atividades propostas.

Assim, passaram a participar mais ativamente, mas com frequência colocando suas ideias em clima de disputa, com vistas a querer verificar quem estava com a razão, e não a título de contribuição ou busca de entendimento. Em alguns casos, procuravam desprezar as ideias dos colegas para tentar fazer valer as suas. $O$ fragmento a seguir ilustra o que foi dito: "Esse cachorro não poderia estar com sarna? A sarna faz cair pelos" colocou o sujeito 09 em tom de indagação. "Não deve ser sarna porque era cachorro de rico, se tinham até babá, cachorro de rico não tem sarna" (Sujeito 20). "Hoje em dia pobre também tem babá" disse o sujeito 09 contestando e, na sequência, refazendo e direcionando a pergunta: "Não pode ser sarna, professora?".

Percebe-se, em meio a essas falas, questões de cunho social e preconceitos arraigados nos sujeitos. Ainda, em meio à construção de suas argumentações, procuravam a validação do professor, em quem acreditavam e a quem atribuíam a palavra final, a explicação correta e definitiva, assim como privilegiam as metodologias transmissivas.

Outro fator de resistência inicial a ser considerado foram as manifestações contrárias da turma a respeito da proposição de um trabalho em grupo em que os alunos deveriam trocar ideias e elaborar uma síntese conjunta a respeito de um tema. A seguir alguns excertos que demonstram essa resistência: "Ah não, professora. Cada um faz o seu, sem grupos." (Sujeito 15) "Aqui é cada um por si, sempre fazemos assim." (Sujeito 09).

O individualismo expresso pelos sujeitos e o ímpeto de manter as práticas de "sempre" alertou ainda mais para a necessidade de desenvolvimento das relações interpessoais nessa turma, para a importância de aprender a conviver e para a necessidade de troca e entrosamento em grupos.

Merece destaque a relutância em assumir as fragilidades dos seus conceitos e em mudar de opinião expressa pelosujeito 09: "Eu posso estar até errado, mas depois que eu tenho uma ideia eu fico com ela, sustento até o final!". Para Carretero e Limón (1994), a resistência em mudar nossas representações iniciais pressupõe a ativação de fatores emocionais, porque "qualquer modificação do conhecimento do aluno pode ser vivida por ele como um desafio a sua identidade” (CARRETERO e LIMÓN 1994, p. 184).

Tais atitudes, como receio em se expor, dificuldade em lidar com a dúvida, resistência em trabalhar em equipe e mudar de opinião, foram compreendidas como um receio natural a tudo que é novo, funcionando como mecanismo 
de defesa. Apesar de compreensíveis, vale ressaltar que elas não foram desconsideradas e sequer receberam o aval da professora-pesquisadora. Pelo contrário, serviram de suporte para o desenvolvimento de um trabalho em prol de uma mudança de atitude necessária.

A mudança, entretanto, não se baseou na repreensão das condutas manifestas. Investiu-se, sim, em uma atitude de interesse para com os alunos e atenção as suas aspirações por meio da escuta atenta, da valorização das contribuições de todos, das palavras de incentivo, das demonstrações de segurança e tranquilidade acerca do processo e da crença na capacidade dos estudantes. Algumas transcrições das falas da professora-pesquisadora ratificam tais afirmações: "Eu disse que as aulas talvez fossem um pouco diferentes do que vocês estão acostumados, é para ser assim mesmo, calma!"; "Estamos em processo de construção das ideias e vocês têm trazido muitas contribuições. Acreditem em si mesmos e exponham seu pensamento."

Faz-se necessário salientar, novamente, a importância do professor no contexto da sala de aula do EPP na EJA, uma vez que, entre outras coisas, "deve estar preparado para interagir empaticamente com esta parcela de estudantes e para estabelecer o exercício do diálogo incentivador" (SOUZA, 2000, p. 127).

Para Coll et al. (1998, p. 15), "a construção do conhecimento na escola exige uma ajuda pedagógica do professor e isso tanto quando se trata da aprendizagem de fatos e conceitos, quanto da aprendizagem de valores, atitudes, normas e outros tipos de conteúdos".

Sendo a autoestima um sentimento desenvolvido ao longo da vida e que pode sofrer flutuações de acordo com situações ou vivências específicas, é preciso investir na qualidade das relações interpessoais a que os alunos estão expostos, tanto dos estudantes em relação ao professor, quanto dos estudantes entre si. Para Brandem (1999), no momento em que o professor adota uma postura diferenciada e passa a aceitar e valorizar seus alunos, a considerá-los capazes de aprender, a julgá-los suficientemente importantes para reservar tempo para ouvi-los, entre outras atitudes, ele contribui para que os alunos se sintam confiantes e preparados para enfrentar as dificuldades e a complexidade inerentes ao processo de aprendizagem (ANTUNES, 2003).

Nesse caminho, gradativamente percebeu-se o enfrentamento dos desafios e a valorização das novas experiências por parte da maioria dos integrantes da turma. Ficou claro, nesse ponto, que a afetividade funcionaria como componente motivacional, uma vez que a construção conjunta de um ambiente escolar de trocas afetuosas e, acima de tudo, respeitoso e encorajador é capaz de despertar a confiança necessária para superação dos temores e o resgate da autoestima dos educandos dessa modalidade de ensino, resultando em uma participação mais ativa dos mesmos.

Durante a produção de uma síntese a ser escrita a respeito da situação-problema apresentada, foi possível notar que os alunos - que antes necessitavam trabalhar com certezas - passaram a assumir uma postura de incerteza, 
iniciando a aceitar e trabalhar com a dúvida, com possibilidades, o que fica destacado em seus escritos, feitos individualmente após a discussão inicial, frequentemente contendo expressões como: "Eu, sujeito 02, acho que..." (Sujeito 02); "Eu imagino que..." (Sujeito 09); "Na minha opinião ..." (Sujeito 12); "O que pode ter acontecido é..." (Sujeito 17).

Pode-se dizer assim que, em função do ambiente favorável, os estudantes foram desenvolvendo sua autonomia, requisito essencial para um trabalho por meio do Educar pela Pesquisa. Nesse sentido, Lima (2004, p. 278) afirma que "é impossível ensinar alguém a ser autônomo, mas é possível, sim, criar um ambiente de liberdade, respeito, escuta e diálogo, que são condições essenciais para o sujeito fazer-se autônomo", conforme se pretendeu que acontecesse nessa investigação.

Nos momentos de comunicação e socialização de saberes de forma oral, jovens e adultos passaram a ouvir, respeitar e a considerar as opiniões alheias quando perceberam que as suas ponderações também estavam sendo ouvidas e valorizadas. A fala de alguns sujeitos reforça essa ideia: "Achei interessante a preocupação com a opinião dos outros, com o que nós, alunos, também achamos." (Sujeito 02). "Achei interessante o respeito a todas as opiniões dadas e a interação entre os colegas e a professora." (Sujeito 24).

Junto a isso, observou-se o estabelecimento de uma relação de parceria entre os alunos e um clima de cooperação - em substituição ao ambiente de disputa presenciado inicialmente - enfatizado pelos diálogos e argumentações em busca de consenso e pela análise de possibilidades para o alcance de objetivos comuns. Nesse sentido, ao invés de somente rebaterem e infirmarem os argumentos dos colegas, na tentativa de desarticulá-los, os alunos conseguiram somar subsídios para reforçar uma tese única, em conjunto. Ainda que não tenha havido unanimidade inicialmente, chegaram a um consenso da turma quanto à possível causa de uma situação-problema apresentada. Para isso, precisaram argumentar, pesquisar e ponderar.

A aceitação da crítica como fator positivo, construtivo e motivador de mudanças foi trabalhada com os alunos em sala de aula, desmistificando a visão inicial que eles possuíam em relação à crítica. "Perceberam como as críticas e colocações dos colegas - que até deixaram alguns aparentemente chateados - auxiliaram na tomada dessa decisão?", incitou a professora-pesquisadora. "É, se não fossem algumas coisas, podíamos até ter ficado com aquelas ideias de antes", declarou o sujeito 26. Como se vê, houve a percepção das críticas como impessoais e construtivas, em razão de elas terem se somado a sugestões enriquecedoras para a obtenção de novos patamares dentro do assunto estudado coletivamente.

Interessante salientar que, apesar da relutância inicial em fazer trabalhos em grupo, ao final das aulas propostas, durante o preenchimento do questionário final, o sujeito 26 reconheceu essa atividade como um fator que contribuiu para a aprendizagem e também relatou-a como a mais interessante. O sujeito 05 também destacou: "As atividades 
que eu mais gostei foram os trabalhos em grupo. Pude aprender com meus colegas". Essas declarações assinalam avanços na tarefa de conviver em grupo, considerada por Jacques Delors e outros autores (1996) como um dos maiores desafios de educar.

Jovens e adultos demonstraram, mais do que a compreensão dos conteúdos teóricos presentes na sequência didática, o gosto por eles e por produzir a partir deles. Era notório que não estavam buscando somente atender a uma mera solicitação da professora e cumprir mais uma tarefa. Estavam, efetivamente, construindo para si, esforçandose por seu interesse para satisfazer objetivos seus e do grupo. Para isso, trabalharam com entusiasmo, chegando, em alguns casos, a produzir além do solicitado. A esse respeito, pensa-seque o fato de ter sido proposta uma situaçãoproblema próxima da realidade dos alunos contribuiu para a mobilização dos mesmos, vindo ao encontro do que pensam Sisto, Oliveira e Fini (2000) que, remetendo-se a Vygotsky, afirmam ter o pensamento sua origem na esfera da motivação, a qual inclui inclinações, necessidades, impulsos, mas, também, afeto e emoção, que devem sempre ser levados em conta.

Paulo Freire (1996, p. 67) expressa preocupação com a questão da afetividade ao indagar: "Como ser educador se não desenvolvo em mim a indispensável amorosidade aos educandos com quem eu me comprometo e ao próprio processo formador de quem eu sou parte?". A frieza e o distanciamento nas relações interpessoais em sala de aula dificultam - se não impedirem - a aprendizagem de qualquer tipo de conteúdo. Por isso, julga-se que a relação horizontal entre professores e alunos, sem acomodação ou omissão de qualquer parte, deve ser marcada pelo apreço recíproco e precisa substituir a verticalidade tradicionalmente assumida entre os agentes do processo educacional. Assim, o foco da mediação pedagógica deve ser o aluno de maneira integral, abrangendo seus interesses, pontos de vista, sentimentos, dificuldades e potencialidades, aspectos que o Educar pela Pesquisa beneficia.

\section{Conclusão}

Ao final dessa investigação, concluiu-se que a prática do Educar pela Pesquisa exige e favorece o trabalho de desenvolvimento dos conteúdos atitudinais na EJA, uma vez que, por meio dos momentos de questionamento, construção de argumentos e comunicação que proporciona, torna-se uma ferramenta contemplativa das contribuições que todos têm a dar, promove o exercício da ponderação e abre espaço para a mediação de possíveis conflitos. Nesse sentido, é fundamental a atenção do professor às peculiaridades dos educandos jovens e adultos para que se invista no incentivo diante das dificuldades, no reforço da autonomia e autoestima em benefício não só de sua permanência em sala de aula, mas também de sua participação ativa enquanto sujeito da sua aprendizagem, no gosto por experenciar 
novos caminhos e possibilidades de ensino e na ampliação de sua consciência para que, cientes do seu inacabamento, saibam que podem e precisam ir além do que já são.

Cientes da complexidade que conforma o ser humano, certamente a análise realizada não esgotou o tema, nem deu conta de esmiuçar suas várias nuances. Contudo, as considerações feitas nesse artigo lançam luz sobre as possibilidades de qualificação da aprendizagem advindas da atenção à dimensão afetiva na EJA e, por outro lado, pressupõem a contraproducência da não consideração dos aspectos atitudinais em sala de aula.

\section{Referências}

ANTUNES, Celso. Relações interpessoais e autoestima: sala de aula como um espaço de crescimento integral. Petrópolis, RJ: Vozes, 2003.

BRANDEN, Nathaniel. Autoestima no trabalho: como pessoas confiantes e motivadas constroem organizações de alto desempenho. Rio de Janeiro: Campus, 1999.

CAMARGO, Poliana da Silva Almeida Santos. EJA e a teoria das representações sociais:influências no processo de ensino-aprendizagem. In: X Congresso Nacional de Educação; I Seminário Internacional de Representações Sociais, Subjetividade e Educação. Anais ... Curitiba: PUCPR, 7 a 10 de novembro de 2011, p. 9824-9842. Disponível em: <http://educere.bruc.com.br/CD2011/pdf/5446_3710.pdf>. Acesso em: 28 out. 2015.

CARRETERO, M.; LIMÓN, M. La construccción del conocimiento histórico: algumas cuestiones pendientes de investigación. Cuadernos de Pedagogia, n. 221, p. 24-26, 1994. Disponível em: <http://dialnet.unirioja.es/servlet/articulo?codigo=35692>. Acesso em: 05 ago. 2015.

CODO, W.; GAZZOTTI, A. A. Trabalho e afetividade. In: CODO, W. (Org.). Educação: carinho e trabalho. Petrópolis: Vozes, 1999. p. 48-59.

COLL, César; POZO, Juan Ignacio; SARABIA, Bernabé; VALLS, Enric. Os conteúdos na reforma: ensino e aprendizagem de conceitos, procedimentos e atitudes. Porto Alegre: Artes Médicas, 1998.

CORREA, Licínia Maria et al. Os significados que os jovens e adultos atribuem à experiência escolar. In: REUNIÃO ANUAL DA ANPED, 26., 2003. Anais eletrônicos ... Poços de Caldas, MG, out. 2003. p. 1-18. Disponível em: <www.anped.org.br/reunioes/26/ trabalhos/liciniamariacorrea.rtf>. Acesso em: 06 ago. 2015.

DELORS, Jacques et al. Educação, um tesouro a descobrir: relatório para a UNESCO da Comissão Internacional sobre Educação para o século XXI. UNESCO/MEC, 1996. Disponível em: <http://ftp.infoeuropa.eurocid.pt/database/000046001-000047000/0000 46258.pdf>. Acesso em: 12 out. 2015.

DEMO, Pedro. Educar pela Pesquisa. 8. ed. Campinas, SP: Autores Associados, 2007.

FREIRE, Paulo. Pedagogia da Autonomia. Saberes necessários à prática educativa. São Paulo: Paz e Terra, 1996. 
FREIRE, Paulo; FAUNDEZ, Antonio. Por uma pedagogia da pergunta. 4. ed. Rio de Janeiro: Paz e Terra, 1998.

LIMA, Valderez Marina do Rosário. Pesquisa na sala de aula: um olhar na direção do desenvolvimento da competência social. In: MORAES, R.; LIMA, V. M. R. (Org.). Pesquisa em sala de aula: tendências para a educação em novos tempos. 2. ed. Porto Alegre: EDIPUCRS, 2004. p. 275-292.

MORAES, Roque; GALIAZZI, Maria do Carmo. Análise Textual Discursiva. 2. ed. Ijuí: Editora Unijuí, 2011. 224p.

MORAES, Roque; GALIAZZI, Maria do Carmo; RAMOS, Maurivan Güntzel. Pesquisa em sala de aula: fundamentos e pressupostos. In: MORAES, Roque; LIMA, Valderez Marina do Rosário (Orgs.). Pesquisa em sala de aula: tendências para a educação em novos tempos. 2. ed. Porto Alegre: EDIPUCRS, 2004. p. 9-24.

POZO, Juan Ignacio; CRESPO, Miguel Angel Gómez. A aprendizagem e o Ensino de Ciências: do conhecimento cotidiano ao conhecimento científico. 5. ed. Porto Alegre: Artmed, 2009.

RAMOS, Maurivan Güntzel; LIMA, Valderez Marina do Rosário; ROCHA-FILHO, João Bernardes da. A Pesquisa como prática na sala de aula de Ciências e Matemática: um olhar sobre dissertações. Alexandria - Revista de Educação em Ciência e Tecnologia, v. 2, n. 3, p. 53-81, nov. 2009. Disponível em: <http://alexandria.ppgect.ufsc.br/files/2012/03/maurivan.pdf>. Acesso em: 03 ago. 2015.

SISTO, F. F.; OLIVEIRA, G. C.; FINI, L. D. T. (Orgs.). Leituras de psicologia para formação de professores. Petrópolis: Vozes, 2000. SOUZA, João Francisco. A Educação de Jovens e Adultos no Brasil e no Mundo. Recife, PE: Edições Bagaço, 2000.

YIN, Robert K. Estudo de caso: planejamento e métodos. Trad. Daniel Grassi. 3. ed. Porto Alegre: Bookman, 2005.

ZABALA, Antoni. A prática educativa: como ensinar. Porto Alegre: Artmed, 1998.

Recebido em: julho/2016

Aceito em: novembro/2016

\section{Endereço para correspondência:}

Thelma Duarte Brandolt Borges

Av. Ipiranga, 6681

90619-900 Porto Alegre, RS, Brasil

<thelmadbb@hotmail.com> 